\title{
EVALUATION OF THE EFFECT OF MAGNITUDE OF SOFT TISSUES SURGICAL TRAUMA ON PERI-IMPLANT SOFT TISSUES STABILITY. (RANDOMIZED CONTROL TRIAL)
}

\author{
Hesham S. Abdel-Moneim*, Radwa T. Elsharkawy** and Ahmed Roshdy Radwan***
}

\begin{abstract}
Peri-impant soft tissues stability became an increasingly thought after goal nowadays in almost every dental implant surgery especially in the esthetic zone, despite being totally over looked in the early stages of the oseointegration era. Implantologists previously focused mainly on achieving oseointegration and considered it to be the bench mark for dental implants success regardless to the esthetic outcomes. With the rise of esthetic dentistry and the use of computer guided technology in surgeries and restoration fabrication, peri implant soft tissues health and stability became of huge concern and a corner stone in dental implants overall success and survival longevity evaluation index. So this study aims to evaluate the effect of the minimally invasive implant surgeries versus the conventional flapped surgical procedures on the peri implant soft tissue around the dental implants. Promising results were postulated from the current study showing a marked superiority of health, speed of recovery, esthetics and stability of the peri implant soft tissues around dental implants placed by minimally invasive surgical protocols versus the conventional flapped surgical techniques. Thereby, concluding that minimally invasive surgical techniques results in an overall better dental implants outcomes aided by the advanced technology in both dental implants installations and final restorations.
\end{abstract}

KEY WORDS: Dental implants, peri-implant tissues, implant soft tissue esthetics, minimally invasive implant surgeries, implants soft tissue stability.

\section{INTRODUCTION}

As periodontal soft tissue in natural teeth functions to stabilize the dentition and provides a biological seal between the external environment and the inside of the body, this soft tissue barrier also exists all around dental implants and has a significant role in dental implants survival and health. Although, both soft tissue interfaces function similarly, however they exhibit different anatomical features, and if the peri implant soft tissue was not respected and properly maintained implant and peri-implant diseases could result. ${ }^{(1)}$

\footnotetext{
* Lecturer of Oral and Maxillofacial Surgery , Faculty of Dentistry, Cairo University.

** Lecturer of Oral Biology, Faculty of Dentistry, Future University in Egypt.

***2ecturer Assistant of Fixed Prosthodontics , Faculty of Dentistry, Cairo University.
} 
Collagen fibers adhere circumferentially and parallel to the trans-gingival region of the implant abutment surfaces leading to a weaker interface. This adhesion cannot tolerate mechanical forces as efficiently as the toughly attached Sharpeys fibers of the natural teeth. Moreover as dental implants lack periodontal ligament vasculature thereby the intimately surrounding tissues (crestal bone and peri implant soft tissue seal) has a scarce blood supply. Also, the surgical trauma from implant insertion procedure results in fibrosis at the implant abutment interface, which hampers the vascularization to the adjacent tissues. This diminished vascularization can reduce the defense of the peri-implant soft tissue against bacterial invasion. Thereby, good oral health and delicate soft tissue handling and manipulation are crucial for successful long term results. ${ }^{(1,2,3)}$

In two stage procedure and bone level implants, repeated abutment connection and disconnection of bone level implants could injure the mucosal barrier leading to apical migration of the biological seal. Thereby early peri implant bone resorption. Abrahamsson et al. has described this observation in a study using platform matched connections, with similar results were documented for platform shifting implants but to a fewer extent. All concluding that the number of implant abutment interface manipulations should be minimized to avoid damaging the soft tissue mucosal barrier and the consequential peri-implant bone affection and subsequent resorption. ${ }^{(4,5,6)}$

Clinical success of dental implants were previously linked to their osseointegration, however prosthetic biomechanics, peri-implant soft tissue health and patients oral hygiene are the crucial elements for dental implants long term success. Although dental implants osseointegration became a nearly predictable procedure with expected outcomes, and as it was solely relied on for the measurement of denal implants success, nowadays other parameters as the peri-implant soft tissue condition became more important especially in the esthetic zone. ${ }^{(7,8,9)}$

Post restorative resorption in all directions (3D) of the alveolar bone around dental implants have long been attributed to be an unavoidable consequence of implant surgery, where it has been documented that crestal bone loss around dental implants typically reaches around $2 \mathrm{mms}$ apical to the implant-abutment connection. This position appears to be nearly constant, regardless to where the implant abutment connection is actually located relative to the initial level of the alveolar bony crest. ${ }^{(10,11)}$

When implants are installed by surgical soft tissue flaps there are generally some form of bone resorption. This is strongly attributed to the decrease in the blood supply to the bone around the implants after flap elevation thereby increasing the magnitude of crestal bone loss. ${ }^{(11)}$

Minimally invasive implant surgeries are not novel, indeed they were practiced before the advent of the osseointegration era. Then those techniques were abandoned because of the principles of osseointegration that dictated a submerged healing as a requirement for implant integration to the bone bed. With the disproving of that concept the flapless approaches re-rose in literature. The benefits of minimally invasive implant surgeries compared to the open flap (invasive) approaches are the reduction of the surgical time, significant reduction or even elimination of postoperative pain, edema, bleeding and ecchymosis, reduction of postoperative functional limitations, optimal esthetics based on the respect of the gingival and papillary integrity. ${ }^{(12,13)}$

These minimally invasive techniques proved to be of great benefits specially with the advancement in technology and introduction of computer assisted and guided surgeries, which not only reduce the surgical time, increase the surgical quality and ensure proper implant three dimensional alignment but also ensures maximum preservation of the sur- 
rounding soft tissue which is now considered to be the corner stone for a successful esthetic dental implant outcome. ${ }^{(12,14)}$

The stability of peri implants soft tissues are highly mandatory when it comes to implants insertion in the esthetic zone, thereby dictating the need for minimal surgical intervention to predict a near perfect pink esthetic outcome. Therefore, the aim of this study was to evaluate the effect of the minimally invasive implant surgeries versus the conventional flapped surgical procedures on the peri implant soft tissue around the dental implants.

\section{MATERIALS AND METHODS}

This study was a double blinded, parallel-group randomized controlled clinical trial. Patients were allocated into 2 groups with allocation ratio 1:1. The study was conducted on 14 male patients, patients enrolled in this study were divided into two groups in which a total of 16 dental implants were installed. Group (A) control, received 7 dental implants* which were installed using conventional surgical protocol, while group (B) intervention, received 9 dental implants which were installed via minimally invasive surgical techniques (flap less , mini incision or trans mucosal)( fig. 1) .

\section{Selection criteria were;}

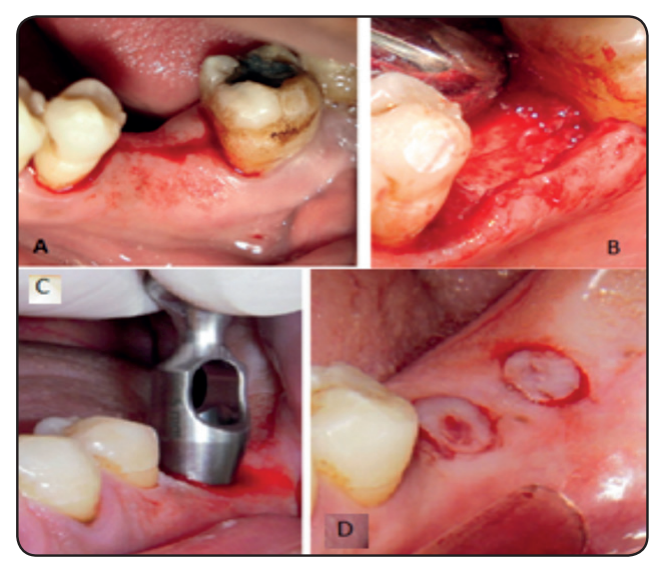

Fig. (1) Showing A; mini incision,B; conventional flapped surgery. C; tissue punch D; flapless trans mucosal surgery.
- Patients should be free from any systemic condition that might affect the outcomes, or even contraindicate the surgical intervention.

- Edentulous maxillary or maxillary areas with no history of previous attempts for replacing the lost dentition.

- Sufficient width and height of the alveolar bone which required no additional procedures.

All surgical procedures were performed under local anesthesia (articaine hydrochloride* 4\% with 1:100,000 epinephrine. Oral prophylactic antibiotic dose was started one hour before surgery (clindamycin* $300 \mathrm{mg}$ ), Immediately before surgery the patient rinsed with Chlorohexidine Gluconate** $0.1 \%$ mouth wash.

For group A a Para-crestal incision was made along the edentulous area with one or two short releasing incisions. Full thickness mucoperiosteal flap was raised using a mucoperiosteal elevator. And the dental implants osteotomy was then prepared by sequential drilling till the desired diameter followed by the insertion of the dental implant and closure of the flap via 4/0 vicryl sutures. For group B several minimally invasive techniques were employed including

- Tissue punch technique using a tissue punch

- Mini incision, via a crestal mucosal incision slightly larger than the proposed implant diameter without reflection of the mucoperiosteium.

- Transmucosal flapless where the drilling was done directly through the gingiva without any soft tissue procedure.

Crestal bone height was evaluated using Cone Beam Computed Tomographys (cb CTs) taken immediately post-operative and 4 months later. Measurements were taken from the height of the healing cap to the alveolar bone crest around the

* TRI Dental Implants Int. AG ,Bösch 80A, CH-6331 Hünenberg, Switzerland. 
implant in the buccal, lingual, mesial and distal aspects of the implants. Soft tissue stability (primary outcome) was evaluated via series of soft tissue impressions were taken post-operatively at intervals of 1 week, 2 months and 4 months to fabricate stone models. The resultant models were divided along the bucco-lingual and mesio-distal axis of the implants, also they were digitized and observed to monitor the behavior of the soft tissue around the dental implants placed by both protocols.

After osseointegration (4 months) the implants were loaded using custom made CAD CAM (designed and milled) titanium abutments and supra structures (fig. 2).

Statistical analysis was performed via Microsoft excel statistical analyzer, AVERAGE, STDEV and $\mathrm{P}$ value calculated by $\mathrm{T}$ test to compare variables



Fig. (2) Showing the loading of a dental implant of group B after osseointegration (4 months), using custom made (CAD CAM) titanium abutment and custom made Full CAD CAM zirconium crown. between the two groups. The results were considered statistically significant if the $p$ value was $\leq 0.05$.

\section{RESULTS}

The crestal bone height around the dental implants was assessed via cone beam CTs taken immediately post operative and after 4 months, so the amount of bone loss could be evaluated. The results of group A (conventional surgical protocol) showed that the average amount of bone loss around the installed implants was $1.11 \mathrm{mms}$. The results of group B (minimally invasive techniques) showed that the average amount of bone loss around the implants was averaging $0.36 \mathrm{~mm}$. (chart 1)

The soft tissue stability has been evaluated were group A (fig. 3) showed that the average amount of soft tissue alteration (edema followed by regression) on the buccal side of the implants was $1.56 \mathrm{mms}$, lingual was $1.22 \mathrm{mms}$, mesial was $1.1 \mathrm{mms}$, while distal was $1.2 \mathrm{mms}$, with a mean of $1.11 \mathrm{mms}$. The results of group B (fig. 4) (minimally invasive techniques) showed that the average amount of soft tissue alterations on the buccal side of the implants was $0.59 \mathrm{~mm}$, lingual was $0.58 \mathrm{~mm}$, mesial was 0.71 $\mathrm{mm}$, while distal was $0.55 \mathrm{~mm}$, thus averaging 0.6 $\mathrm{mm}$ (table 1) The results statistically analyzed and the $\mathrm{p}$ value was calculated (statistically significance mark point of $\mathrm{p} \leq 0.5$ ) using windows excel $\mathrm{t}$ test and the result was found to be $\mathrm{p}=0.0483$ denoting low statistical significance. 


\begin{tabular}{|c|c|c|c|c|c|}
\hline & & B & $\mathbf{L}$ & $\mathbf{M}$ & D \\
\hline \multirow{4}{*}{$\begin{array}{c}\text { Implant } \\
\# 1\end{array}$} & 1 week & 0 & +0.25 & 0.4 & 0.75 \\
\hline & 1 month & 1.30 & 1.25 & 0.5 & 1.4 \\
\hline & 4 momths & 1.35 & 1.35 & 0.75 & 1.4 \\
\hline & Soft tissue recession & -1.35 & -1.55 & -0.35 & -0.65 \\
\hline \multirow{4}{*}{$\begin{array}{l}\text { Implant } \\
\# 2\end{array}$} & 1 week & 0.75 & 1 & 1.1 & 1.2 \\
\hline & 1 month & 2 & 2.25 & 1.75 & 1.9 \\
\hline & 4 months & 2.2 & 2 & 1.8 & 2 \\
\hline & \begin{tabular}{|l|} 
Soft tissue recession \\
\end{tabular} & -1.45 & -1 & -0.75 & -0.8 \\
\hline \multirow{4}{*}{$\begin{array}{l}\text { Implant } \\
\text { \#3 }\end{array}$} & 1 week & 0.75 & 0.8 & 0.5 & 0.3 \\
\hline & 1 month & 1.6 & 1.8 & 1.5 & 2.1 \\
\hline & 4 months & 2 & 2.25 & 1.7 & 2.2 \\
\hline & Soft tissue recession & -1.25 & -1.45 & -1.2 & -1.9 \\
\hline \multirow{4}{*}{$\begin{array}{l}\text { Implant } \\
\quad \# 4\end{array}$} & 1 week & 0 & 0.25 & 0.45 & 0.5 \\
\hline & 1 month & 1.25 & 0.75 & 1 & 1 \\
\hline & 4 months & 1.5 & 1.25 & 1.5 & 1.25 \\
\hline & Soft tissue & -1.5 & -1 & -1.05 & -0.75 \\
\hline \multirow{4}{*}{$\begin{array}{c}\text { Implant } \\
\# 5\end{array}$} & 1 week & 0.5 & +0.25 & +0.75 & +0.25 \\
\hline & 1 month & 1.25 & 0.75 & 0.75 & 0.75 \\
\hline & 4 months & 1.75 & 1.25 & 1.25 & 1.10 \\
\hline & Soft tissue recession & -1.25 & -1 & -1.5 & -1.35 \\
\hline \multirow{4}{*}{$\begin{array}{l}\text { Implant } \\
\quad \# 6\end{array}$} & 1 week & 0.5 & 0.75 & 1 & +0.5 \\
\hline & 1 month & 1.45 & 1.75 & 2.25 & 0.75 \\
\hline & 4 months & 1.75 & 2.15 & 2.75 & 1.25 \\
\hline & $\begin{array}{l}\begin{array}{l}\text { Soft tissue } \\
\text { recession }\end{array} \\
\end{array}$ & -1.25 & -1.35 & -1.75 & -1.75 \\
\hline \multirow{4}{*}{$\begin{array}{c}\text { Implant } \\
\# 7\end{array}$} & 1 week & 0.75 & 0.8 & 0.5 & 0.3 \\
\hline & 1 month & 1.6 & 1.8 & 1.5 & 2.1 \\
\hline & 4 months & 2 & 2.25 & 1.7 & 2.2 \\
\hline & $\begin{array}{l}\text { Soft tissue } \\
\text { recession }\end{array}$ & -1.25 & -1.45 & -1.2 & -1.9 \\
\hline \multirow[t]{4}{*}{$\begin{array}{l}\text { Implant } \\
\# 8\end{array}$} & 1 week & 2.8 & 2.4 & 2.3 & 2 \\
\hline & 1 month & 3.3 & 3 & 3 & 2.5 \\
\hline & 4 months & 3.5 & 2.8 & 3.2 & 2.5 \\
\hline & $\begin{array}{l}\text { Soft tissue } \\
\text { recession }\end{array}$ & -0.7 & -0.4 & -0.9 & -0.5 \\
\hline
\end{tabular}




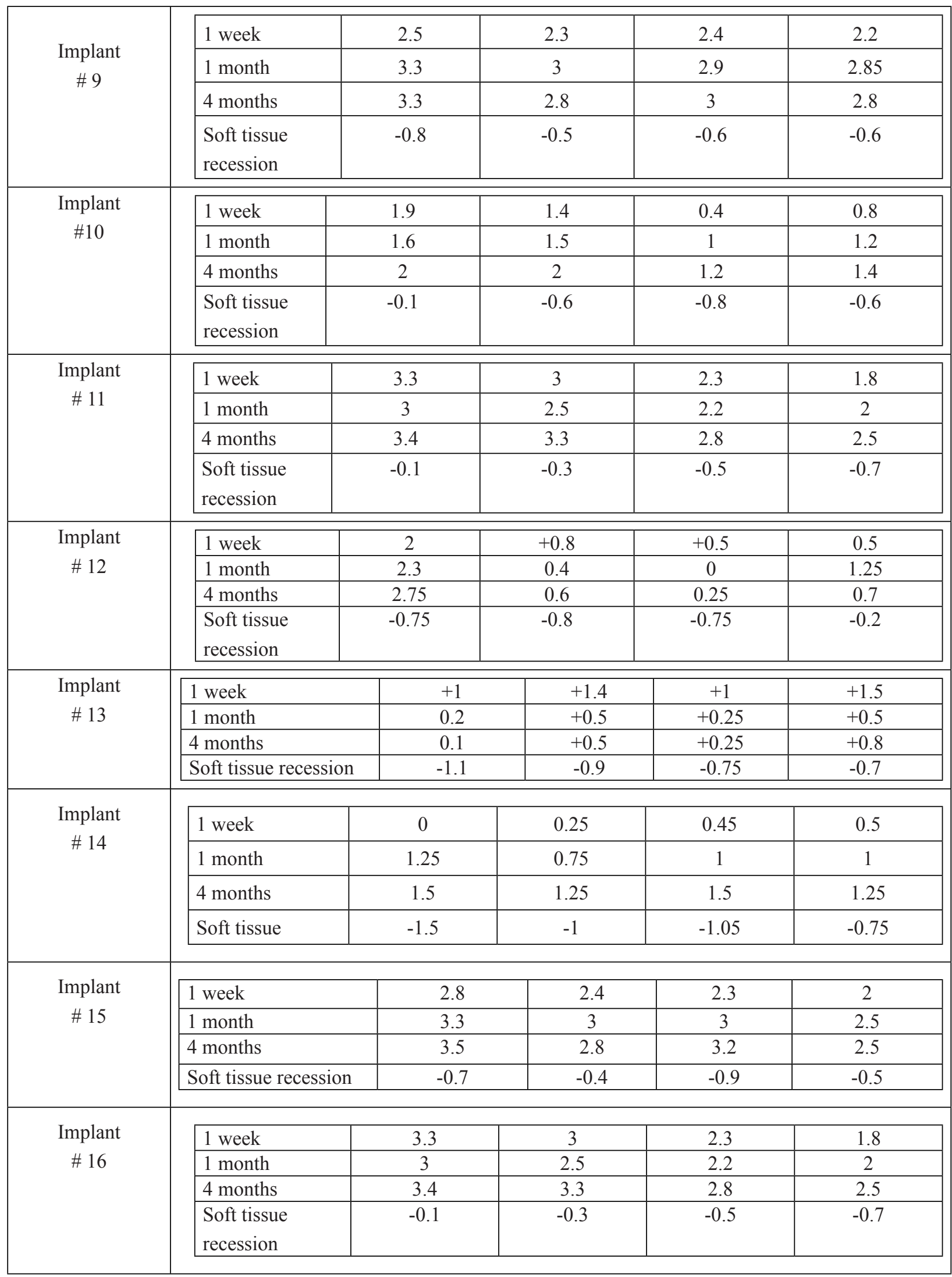




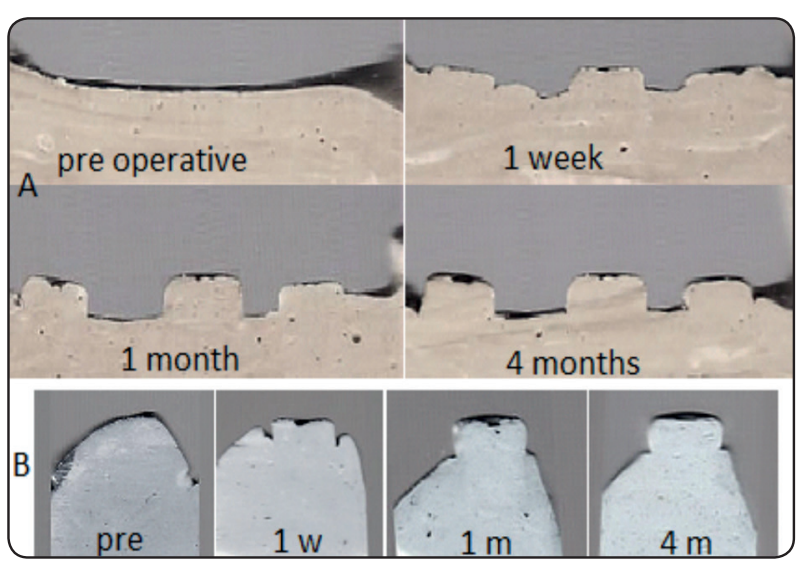

Fig. (3) Showing Soft tissue of group A. A; Casts sectioned along the mesio distal axis of the implants. B; Casts sectioned along the bucco lingual axis of the implant.

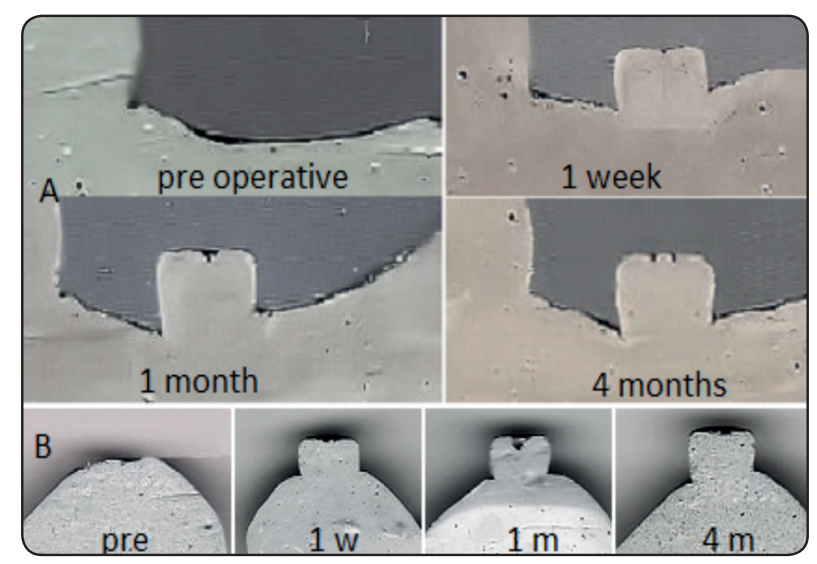

Fig. (4) Showing Soft tissue of group B. A; Casts sectioned along the mesio distal axis of the implants. B; Casts sectioned along the bucco lingual axis of the implant.

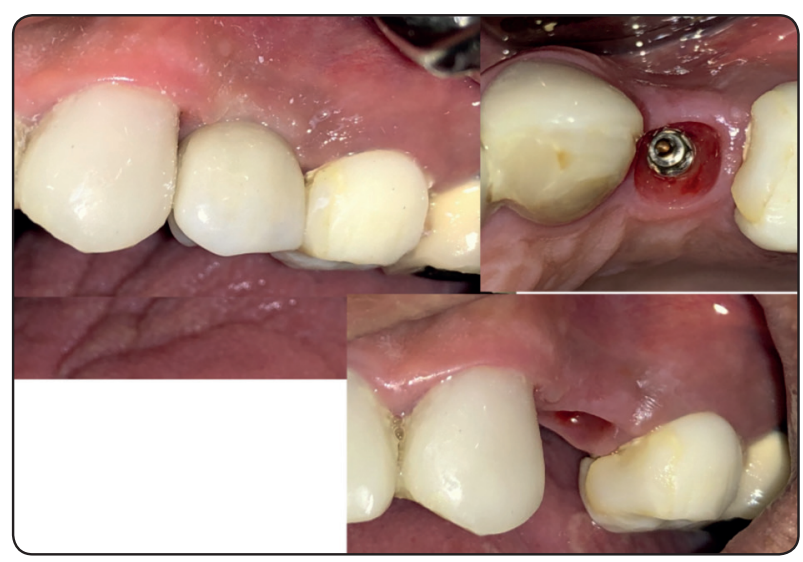

Fig. (5) Showing the soft tissue condition of a case of the minimally invasive group at the time of loading.

\section{DISCUSSION}

Cases of the current study experienced nearly no gingival recession after implant placement using a flapless implant protocols. The soft tissue level around the implants increased by $0.7 \mathrm{mms}$ at 1 week, $0.2 \mathrm{mms}$ at 1 month and resolved to $0 \mathrm{~mm}$ by 4 months, indicating that the adjacent mucosa enlarged after the surgery and then returned to the baseline. These results suggested that minimally invasive procedures are superior in maintaining the original soft tissue form surrounding dental implants.

The minimally invasive implant surgeries have shown to have benefits over conventional surgical protocol when it comes to crestal bone preservation and reduction of peri implant soft tissue alterations. The results of the current study have denoted some of these advantages. From the results this study it has been found that the mean of bone loss after conventional flapped surgical protocol of implant placement was $1.11 \mathrm{mms}( \pm 0.2 \mathrm{~mm})$, while on the other hand the average amount of bone loss after minimally invasive implant surgeries was 0.36 $\mathrm{mm}( \pm 0.2 \mathrm{~mm})$. Thus it indicates that the flapless technique saved approximately $0.75 \mathrm{~mm}$ of the peri implant bone, which in fact a precious amount of bone that significantly improves stability and even the life span of the installed implants.

As an open flap protocol implies the elevation of the mucoperiosteum from the underling alveolar bone to access the surgical site, this reflection results in the disruption of the alveolar bone blood supply which relies to a great extent on the vasculature of the overlying periosteum. So after implant placement via an open surgery the crestal bone significantly loses most of its blood supply thereby resulting in an accelerated crestal bone loss. On the contrary the minimally invasive techniques results in minimal disruption of the sub periosteal plexus thereby maximizing the preservation of the crestal bone levels around the installed implants and indirectly the preservation of the overlying peri implant soft tissues. ${ }^{(11,12)}$ 
As it was documented that most of the recession occurred during the first 3 months postoperatively, this ensures with the results of the present study which stated that most of the crestal bone loss occurred within 4 months period after dental implants placement. Also Gomez and Roman ${ }^{(15)}$ supported the outcomes by reporting that whenever it comes to crestal bone, higher bone loss rates usually occur with widely mobilized surgical flaps where the interpositioned bone in proximity to the adjacent tooth is denuded from its periosteum thus affecting the viability of the bone and mucosa, thereby leading to unpredictable levels of resorption of the interproximal bone. They also recommended limited flap designs to minimize interproximal crestal bone loss and possible papillary loss.

Crestal bone loss might also occur when insufficient soft tissues are present to establish a biological seal around the implants, which will isolate the crestal bone and protect it from the external environment. This denotes that proper installation of the implant affects the magnitude of initial crestal bone loss, as in cases of infra bony implant placement this will increase the initial bone loss to establish the desired biological seal. It was also stated by Hermann et al that merely $3 \mathrm{mms}$ of peri-implant mucosa is essential to form a mucosal barrier (biological seal) for the dental implant, however remodeling of the peri implant crestal bone might occur to create space so that a biological seal could be established, that in turn would isolate the peri implant bone and protect it from the oral environment. ${ }^{(14,15,16)}$

Efforts were made by many researchers to reduce the amount of crestal bone loss after implant surgeries among these efforts was the rebirth of the single stage flapless implant surgery to benefit its' numerous pros. This has been supported by a research which stated that among the benefits of less intervention were reduced postoperative swelling, reduced discomfort, minimal bleeding and improved post-operative quality of life without any limitations. It was also stated that flapless implant protocol improved both the osseointegration of dental implants, the bone height and soft tissue levels around implants. ${ }^{(17)}$

From that and as the attached gingiva and papillae are strictly adherent to their underlying bone, and as the levels of the bone around dental implants are preserved and bone loss minimized , so does the soft tissue around the implants.

With the rise of and increased awareness to aesthetics in dentistry, a greater focus was made on how to reduce the impact that a surgical procedure could have on the pink tissues. And as dental implants not only restore function but also esthetics so the surgical protocols implemented should target the maintenance and optimization of the peri implant soft tissue health and overall profile.

When noting the response of the soft tissue around dental implants the current study revealed that implants placed via conventional surgical protocols showed soft tissue alterations (enlargement or edema then recession) of an average of $1.27 \mathrm{mms}$. On the other hand the results of implants placed by minimally invasive techniques showed soft tissue alterations (enlargement or edema then recession) of an average of $0.6 \mathrm{~mm}$ and the calculated $\mathrm{p}$ value of 0.4835 indicating statistically significant results. From that it could be postulated that the minimally invasive implant surgery surpassed conventional flap technique regarding the preservation of the soft tissue profiles and thereby better esthetic outcomes.

Monitoring soft tissues behavior has been under the focus of several clinical studies with variable results. Bengazi F. Et al. found that amount of softtissue recession for single stage dental implants have been found to be utterly similar to that of the two-staged approaches. While Small P. and Tarnow D. studied soft tissue changes following implant installations involving both single and two staged techniques, noting coronal migration of the tissues 1 week postoperative, which was attributed to 
inflammatory process, while most of the recession reported occurred during the first 3 months, resulting in the authors' recommendation that definitive final impressions should not be taken till at least 3 months of healing. ${ }^{(19,20)}$

As previously documented that repeated abutment connection and disconnection of bone level implants could negatively affect the mucosal barrier leading to apical migration of the soft tissue biological seal and lead to peri implant bone loss. Also a conclusion has been made that the number of implant abutment interface manipulations should be reduced to avoid damaging the soft tissue mucosal barrier and thereby its deleterious effect on the peri implant bone. ${ }^{(4,5,6)}$

For the longevity of the soft tissue stability (pink esthetics) around dental implants, it has been stated that all elements that induce peri implantitis should be avoided or at least reduced, among these factors are peri implant soft tissue thickness, abutment design, abutment seating, fixture abutment connection design and stability, prosthetic crown design and margins (screw or cement retained) and patient oral hygiene.(21) All these factors comes second to first a properly installed implant fixture governing implant location, angulation and respected soft tissue physiology.

So as its noted that the degree of tissue injury influence the speed and quality of healing, the minimally invasive protocols stated lower degree of soft tissue injury than that which occurred after a more invasive surgical protocol. Thereby the current study supports the concept that minimally invasive surgical techniques are superior to conventional surgical protocols when it comes to reducing bone loss, together with the minimizing edema after implant installation and ensuring stabilization of the pink soft tissues around dental implants which in turn will improve the overall esthetic outcome.

Thus minimally invasive dental implants installation techniques proved to be of huge benefits spe- cially with the ongoing advancement in technology and with the growing era of computer assisted (virtual) planning and guided surgeries, which not only ensure near ideal insertion of the dental implant in all 3 dimensional relations, reduce the surgical time and increase the surgical quality but also guarantees maximum preservation of the surrounding soft tissue which are now considered to be the corner stone for a successful esthetic dental implant outcome.

\section{CONCLUSION}

Minimally invasive dental implant surgical techniques reduced the amount of soft tissue alterations edema followed by recession and reduced the amount of crestal bone loss compared with the conventional open flap surgical techniques.

\section{REFERENCES}

1. Wang, Y., Zhang, Y. \& Miron, R. J. Health, Maintenance, and Recovery of Soft Tissues around Implants. Clin Implant Dent Relat Res 18, 618-634, (2016).

2. Akcali, A. et al. What is the effect of soft tissue thickness on crestal bone loss around dental implants? A systematic review. Clin Oral Implants Res (2016)

3. Puisys, A. \& Linkevicius, T. The influence of mucosal tissue thickening on crestal bone stability around bonelevel implants. A prospective controlled clinical trial. Clin Oral Implants Res 26, 123-129, (2015)

4. Abrahamsson I, Berglundh T, Wennström J, Lindhe J. The peri-implant hard and soft tissues at different implant systems. A comparative study in the dog. Clin Oral Implants Res. 1996 Sep;7(3):212-9.

5. Rodriguez, X. et al. The effect of abutment dis/ reconnections on peri-implant bone resorption: a radiologic study of platform-switched and non-platformswitched implants placed in animals. Clin Oral Implants Res 24, 305-311, (2013)

6. Molina, A., Sanz-Sanchez, I., Martin, C., Blanco, J. \& Sanz, M. The effect of one-time abutment placement on interproximal bone levels and peri-implant soft tissues: a prospective randomized clinical trial. Clin Oral Implants Res, (2016) 
7. Seung-Mi Jeong; Byung-Ho Choi; Jingxu Li; Han-Sung Kim; Chang-Yong Ko; Jae-Hyung Jung; Hyeon-Jung Lee; Seoung-Ho Lee and Wilfried. Engelke, Wonju and Seoul, South Korea, and Göttingen, Germany. Flapless implant surgery: an experimental study. Oral Surg Oral Med Oral Pathol Oral Radiol Endod. 104;24-28,2007.

8. Grusovin, M.G., Coulthard, P., Jourabchian, E., Worthington, H.V., and Esposito, M.A. Interventions for replacing missing teeth: maintaining and recovering soft tissue health around dental implants. Cochrane Database Syst Rev. 2008; : CD003069

9. Du-Hyeong Lee; Byung-Ho Choi; Seung-Mi Jeong; Feng Xuan and Ha-Rang Kim.: Effects of Flapless Implant Surgery on Soft Tissue Profiles: A Prospective Clinical Study . Clinical Implant Dentistry and Related Research. Online publication date: 1-Sep-2009.

10. Hermann, J.S.; Schoolfield, J.D.; Nummikoski, P.V. and et al. Crestal bone changes around titanium implants: A methodologic study comparing linear radiographic with histometric measurements. Int J Oral Maxollofac Implants. 16(4);475-485,2001.

11. Teresa Lombardi, Federico Berton, Stefano Salgarello, Erika Barbalonga , Antonio Rapani, Francesca Piovesana, Caterina Gregorio, Giulia Barbati, Roberto Di Lenarda and Claudio Stacchi Factors Influencing Early Marginal Bone Loss around Dental Implants Positioned Subcrestally: A Multicenter Prospective Clinical Study. J. Clin. Med. 2019, 8(8), 1168.

12. Ribes Lainez N, Monreal Bello A, Fuster Torres MA, Peñarrocha Oltra D, Peñarrocha Diago M. Periimplant soft-tissue and bone levels around dental implants with different neck designs and neck surface treatments: A retrospective cohort study with 3-year follow-up. J Oral Science Rehabilitation. 2017 Dec;3(4):16-23.

13. RosaJC, RosaAC, FrancischoneCE, Sotto-MaiorBS. Esthetic outcomes and tissue stability of implant placement in compromised sockets following immediate dentoalveolar restoration: results of a prospective case series at 58 months follow-up.Int J Periodontics Restorative Dent. 2014Mar-Apr;34(2):199-208. PMid:24600656. http://dx.doi.org/10.11607/prd.1858.

14. Christoph H.F. Hämmerle and Dennis Tarnow. The etiology of hard- and soft-tissue deficiencies at dentalimplants: A narrative review. J Periodontol.2018;89 (Suppl 1):S291S303.

15. German Gomez and Roman.: Influence of Flap Design on Peri-implant Interproximal Crestal Bone Loss around Single-tooth Implants. Int J Oral Maxillofac Implants. $16 ; 61-67,2001$.

16. Rungcharassaeng K, KanJY, Yoshino S, MorimotoT, ZimmermanG. Immediate implant placement and provisionalization with and without a connective tissue graft: an analysis of facial gingival tissue thicknessInt $\mathrm{J}$ Periodontics.Restorative Dent. 2012Dec;32(6):657-63.

17. Anumala D, Haritha M, Sailaja S, Prasuna E, Sravanthi G, Reddy NR. Effect of Flap and Flapless Implant Surgical Techniques on Soft and Hard Tissue Profile in SingleStage Dental Implants. J Orofac Sci 2019;11:11-5

18. Kuchler U, Chappuis V, Gruber R, Lang NP, Salvi GE. Immediateimplant placement with simultaneous guided bone regeneration inthe esthetic zone: 10-year clinical and radiographic outcomes.ClinOral Implants Res. 2016;27:253-257.

19. Bengazi, F.; Wennstrom, J.L. and Lekholm, U.: Recession of the soft tissue margin at oral implants. A 2-year longitudinal prospective study. Clin Oral Implants Res. 7;303-310,1996.

20. Small, P. and Tarnow, D.: Gingival recession around implants: a 1-year longitudinal prospective study. Int J Oral Maxillofac Implants. 15; 527-532,2000.

21. Alberto Monje, Angel Insua and Hom-Lay Wang. Understanding Peri-Implantitis as a Plaque-Associated and Site-Specific Entity On the Local Predisposing Factors. J. Clin. Med. 2019, 8, 279. 